\title{
Práticas docente e o uso da tecnologia na Classe Hospitalar Semear
}

\author{
Paulo Adriano Schwingel 1 \\ Emerson Marinho Pedrosa ${ }^{2}$ \\ Cristiane Rose de Lima Pedrosa ${ }^{3}$
}

\begin{abstract}
RESUMO
Este artigo aborda a prática docente e o uso da tecnologia no cotidiano da Classe Hospitalar Semear, ancorado numa investigação que objetivou compreender os processos formativos e a inclusão da tecnologia nesse ambiente. A presente pesquisa é um estudo de caso de natureza qualitativa, em que se considerou a observação dos espaços-tempos coletivos dos docentes, entrevistas e análises de documentos como fonte de dados. A mediação pedagógica com apoio das Tecnologias da Informação e Comunicação (TICs) na Semear, permitiu perceber a individualidade dos sujeitos envolvidos, respeitando os aspectos emocionais e afetivos, geradores de desenvolvimento cognitivo destes pacientes/estudantes, a partir de uma abordagem sistémica e multidimensional valorizando as relações do processo educativo. $\mathrm{O}$ uso da tecnologia em confluência com mediação pedagógica adequada a essa modalidade de ensino possibilita a construção do conhecimento de forma lúdica, prazerosa e divertida, associada às dinâmicas de socialização que são indispensáveis a esse ambiente pedagógico.
\end{abstract}

PALAVRAS-CHAVE: Classe hospitalar. Educação. Tecnologia.

Teaching practices and the use of technology in the Semear Hospital Class

\footnotetext{
1 Doutor. Universidade de Pernambuco, Petrolina, Pernambuco, Brasil. Orcid: https://orcid.org/0000-0002-29353403. E-mail: paulo.schwingel@upe.br.

2 Doutorando. Universidade Federal do Rio Grande do Sul, Porto Alegre, Rio Grande do Sul, Brasil. Orcid: https://orcid.org/0000-0002-7375-8889. E-mail: emerson.pedrosa@ufrpe.br.

${ }_{3}^{3}$ Mestranda. Universidade de Pernambuco. Especialista Classe Hospitalar. Prefeitura da Cidade do Recife, Recife, Pernambuco, Brasil. Orcid: https://orcid.org/0000-0003-0018-1406. E-mail: cristianerosepedrosa @ gmail.com.
} 


\begin{abstract}
This paper addresses the teaching practice and the use of technology in the daily life of the Semear Hospital Class, anchored in an investigation that aimed to understand the training processes and the insertion of technology in this environment. The research was developed through a qualitative case study. As a source of data, the observation of the teachers' collective work environment, interviews and document analysis were considered. The results obtained revealed that everyday school situations offer favorable contexts in promoting the learning of students/patients, the zeal beyond the right to education, as well as the humanization of the hospital in contact with the educational possibilities of the child victim of some type of pathology, being a motivational factor for teaching work. The data also pointed to the need for investment in continuing education actions, in order that teaching proposals applicable to the process become effective in school practice.
\end{abstract}

KEYWORDS: Hospital school. Education. Technology.

Prácticas de enseñanza y el uso de tecnología en la clase Hospitalaria Semear

\title{
RESUMEN
}

Este artículo aborda la práctica docente y el uso de la tecnología en la vida diaria de la Clase Semear Hospitalaria, anclada en una investigación con el objetivo comprender los procesos de capacitación y la inclusión de la tecnología en este entorno. La presente investigación es un estudio de caso cualitativo. La observación de los espacios-tiempo colectivos de los docentes, las entrevistas y el análisis de documentos se consideraron como una fuente de datos. La mediación pedagógica con el apoyo de las TIC en Semear, permitió percibir la individualidad de los sujetos involucrados, respetando los aspectos emocionales y afectivos, que generan el desarrollo cognitivo de estos pacientes/estudiantes, desde enfoques sistémicos y multidimensionales, valorando las relaciones del proceso educativo. El uso de tecnologías con mediación pedagógica apropiada para este tipo de enseñanza permite la construcción del conocimiento de una manera lúdica, placentera y divertida asociada con la dinámica de socialización, indispensable para este entorno pedagógico.

PALABRAS CLAVE: Clase hospitalaria. Educación. Tecnología. 


\section{Introdução}

A Educação inclusiva é um importante caminho para o alcance da diversidade, mediante a construção de uma escola presente, com uma proposta pedagógica que atenda às necessidades do educando, em particular àqueles que correm risco de exclusão em termos de aprendizagem e participação no contexto escolar. Diante da pandemia que hoje vivenciamos com o avanço do coronavírus (COVID-19), escolas e universidades ajustam suas metodologias de ensino focadas nas tecnologias para adequar ensino e aprendizagem como uma forma de inclusão e reparação de eventuais danos aos alunos. Uma realidade nas salas de aula regulares, essas tecnologias também estão presentes nas salas inclusivas e especiais. É importante notar que o número de estudos que demonstram a integração das TICs no ambiente educacional hospitalar e seu emprego como ferramenta de suporte à produção de conhecimentos neste ambiente ainda é escasso.

Desafio no ambiente hospitalar, segundo Barros e Santos (2008, p. 134) a falta de perfil e capacitação dos professores destinados a ingressar na realidade de uma classe hospitalar é um fator que pode concorrer negativamente para sua permanência neste ambiente, ou mesmo para o seu melhor desempenho. A presença das TICs nas salas de aula traz consigo uma imensidão de possibilidades e oportunidades. Com elevado número de informações disponibilizadas, seu uso convida à construção de novas práticas sem renunciar à ética da relação humanística a ser vivenciada na relação pedagógica da classe hospitalar.

Na nova realidade tecnológica, o tempo da educação é o tempo da vida. As escolas não vão atender apenas a segmentos restritos de alunos de determinada faixa etária, nível social e educacional. Será preciso que haja ofertas educacionais para alunos de todas as idades e todos os níveis. Também devem ser oferecidas soluções educacionais para pessoas que estejam de forma temporária (por doença, por exemplo) ou permanente (sem moradia, sofrendo de doença crônica etc.) afastadas dos prédios escolares (KENSKI, 2014, p. 124). 
A aptidão humanizadora dos hospitais tende a contribuir com a intervenção educativa. Além disso, a parceria entre as entidades voltadas a educação e aquelas voltadas a saúde do indivíduo proporciona a articulação entre os profissionais envolvidos na inclusão do aluno/paciente. Nesta senda, o uso das tecnologias no ambiente escolar vem trazendo mudanças e impactando na práxis docente. Empresas como a Positivo e a SAE Digital oferecem suporte tecnológico como a mesa educacional alfabeto, interferindo desde a estrutura física necessária, até os materiais e recursos didáticos empregados, onde o professor tem papel fundamental no desenvolvimento das habilidades e competências indispensáveis aos estudantes das novas gerações. Entende-se, desta forma, que a inclusão no mundo tecnológico e digital no atendimento pedagógico hospitalar é também questão de cidadania.

Diante do acelerado crescimento da internet e com o auge das tecnologias móveis associados a smartphones e tablets, as experiências geradas no uso das TICs podem trazer novas propostas educacionais, pondo ao alcance de estudantes e professores um acervo de conteúdos e ferramentas de riqueza inestimável para o ensino e a aprendizagem em todos os campos do saber. Isto se configura num processo ímpar para o desenvolvimento do indivíduo nos âmbitos físico, cognitivo, social e moral, favorecendo sua inserção na sociedade e contribuindo com a formação do sujeito crítico capaz de pensar, questionar e decidir.

Destaca-se daí a importância da revisão dos modelos pedagógicos, que devem incluir na formação inicial docente conceitos, métodos e técnicas que os habilitem para este novo desafio. Segundo Pozo (2005, p. 39), "a aprendizagem tem sido, tradicionalmente, o escudo da aquisição e da mudança de comportamentos”. Neste sentido, a aprendizagem correlacionase a comportamentos moldados paralelamente a aquisição do conhecimento.

A rapidez das inovações tecnológicas nem sempre correspondem à capacitação dos professores para a sua utilização e aplicação, o que muitas vezes, resulta no uso inadequado ou na falta de criação diante dos recursos tecnológicos disponíveis, [...] (SERAFIM, et al., 2011, p. 24). 
O Instituto Nacional de Estudos e Pesquisas Educacionais Anísio Teixeira (INEP) revela, a partir de seus microdados (BRASIL, 2018), que houve um aumento na taxa de matrículas em hospitais no país entre 2013 e 2017. Em 2017 apenas, as matrículas em ambiente hospitalar somavam 20,6 mil de um total de quase 54 milhões de inscritos em todos os níveis de escolaridade básica - da educação infantil ao ensino médio e técnico, incluindo Educação de Jovens e Adultos.

O uso das inovações tecnológicas na práxis pedagógica são elementos de estudo desta pesquisa na Classe Hospitalar Semear, onde a inserção da tecnologia e a adequação da prática é apreendida no dia a dia da classe hospitalar. O estudo torna-se relevante diante da expectativa de crescimento da prática pedagógica em ambientes hospitalares, em particular em Pernambuco, que conta apenas com uma instituição em funcionamento.

\section{O desafio docente ao utilizar-se da tecnologia}

Ao optar por utilizar as tecnologias, o professor deve estar atento aos resultados que se pode alcançar, mediando seu percurso diante da infinitude de trajetos possíveis e vislumbrando sempre o interesse do aprendizado, capaz de proporcionar ao aluno novas experiências e desafios.

Utilizar-se de novas tecnologias na educação não implica necessariamente em trazer novas práticas educacionais, pois podemos com ela de certa forma, vestir o velho com roupa nova, o docente terá que se concentrar no despertar do aluno, tornando-o atento ao que o rodeia, preparando-o para novas situações, imediatas ou não, adaptando-se a modernidade (PEDROSA; LUIZ, 2017, p. 157).

É preciso compreender o desafio do professor, quanto sua percepção no ambiente hospitalar, ao receber o estudante/paciente, vivenciando uma realidade que, para ele, difere da vivenciada em sua escola de origem: calcada, muitas vezes, em seu passado no qual sequer existia o computador. 
Nessa ação pedagógica, o professor é instigado a aprender e desenvolver, concomitantemente, saberes oriundos das TICs e do processo de trabalho neste âmbito, buscando compreender o quanto antes as novas condições que demandem o desenvolvimento desses saberes e adaptação ao contexto que exigem recursos, tempo, prática e experiência.

Neste ideário, Hernandez (1998, p. 42) analisa experiências de formação docente, defendendo sua realização na própria prática do cotidiano escolar como caminho desejável na expectativa de fortalecer as escolas, onde se aprende com a prática e dando sentido ao ensino. Talvez o computador ainda não faça parte da rotina do professor fora do ambiente da escola, mas faça parte da realidade escolar em que atua. Para Almeida (2005, p. 40), em nosso cotidiano empregamos processos e ferramentas de forma tão natural que não nos damos conta de que fazem parte de distintas tecnologias presentes em nossa vida, já incorporados aos nossos hábitos.

Eventualmente, ainda pode ser motivo de constrangimento para o professor a falta de perícia no uso dessas novas tecnologias, muitas vezes já dominadas pelos alunos. Este parece ser mais um elo da nova relação aluno/professor. Sampaio e Leite (1999, p. 15) apontam para a necessidade de uma "alfabetização tecnológica" do professor, onde as tecnologias também são parte da vida diária das pessoas e estão em constante desenvolvimento. O aparato tecnológico representa grande inovação na educação quando sua utilização, permeada por objetivos pedagógicos, favorece o desenvolvimento das produções em colaboração, desenvolvendo o espírito de investigação tanto dos alunos quanto dos professores.

No marco dos processos de ensino e aprendizagem, a capacidade mediadora das TIC pode se desenvolver basicamente, em uma primeira aproximação, em duas direções. Em primeiro lugar, as TIC podem mediar as relações entre os participantes - especialmente os estudantes, mas também os professores - e os conteúdos de aprendizagem. Em segundo lugar, as TIC podem mediar as interações e as trocas comunicacionais entre os participantes, seja entre professores e estudantes, seja entre os próprios estudantes (COLL; MAURI; ONUBIA, 2010, p. 76). 
Existem inúmeros softwares educativos que podem tornar a aprendizagem mais efetiva. Para isso, é necessário que o professor tenha autonomia para ampliar o conhecimento e o horizonte dos seus alunos, possibilitando-lhes liberdade para planejar adequadamente o processo de ensino. A exemplo disso, a ludicidade no ambiente virtual pode proporcionar o resgate do cotidiano infantil, tornando o ambiente hospitalar menos doloroso, favorecendo a humanização na relação pedagógica e hospitalar, minimizando este último, que deixa de ser apenas um espaço de procedimentos clínicos para ser também um espaço pedagógico de inclusão com tecnologia e aprendizagem.

Um importante viés à mudança e/ou quebra de paradigma na educação depende basicamente da boa formação docente:

Bons professores são as peças-chave na mudança educacional. Muitos começam a lecionar sem uma formação adequada, principalmente do ponto de vista pedagógico. Conhecem o conteúdo, mas não sabem como gerenciar uma classe, como motivar diferentes alunos, que dinâmicas utilizar para facilitar a aprendizagem, como avaliar o processo ensino-aprendizagem, além das tradicionais provas (MORAN, 2007, p. 18).

Nesse sentido, qualquer ambiente deve permitir estratégias para a aprendizagem, a fim de se adequar ao maior número possível de indivíduos, a partir do papel do professor, de suas concepções e referenciais de educação que orientam a ação educativa, por vezes trilhando caminhos particulares, variando de conformidade com fatores como interesse, conhecimento do conteúdo, estrutura, motivação, saúde, entre outros. Para que a escola atinja seus objetivos também nesse campo, são necessários recursos tecnológicos ou professores capacitados aliados a projetos pedagógicos que construam uma atuação mais eficiente no espaço escolar, um esforço conjunto da escola como um todo, no sentido de modificar a forma de atuação dos educadores para alcance de uma educação de qualidade. 
É importante frisar que não apenas a inserção das novas tecnologias é que irá melhorar os resultados a ser conquistados, pois elas sozinhas não são "salvadoras da pátria". O bom resultado depende muito mais da participação de seus atores conjuntamente a metodologia aplicada do que do uso de qualquer recurso tecnológico apresentado como inovador.

Nesta perspectiva, a escola, o professor e as transformações sociais ajustadas a essa nova realidade tecnológica pode ser construída baseada em ações em que o professor deverá estar pronto e motivado para despertar o interesse ao aprendizado em conjunto com os sujeitos envolvidos neste processo, proporcionando a interação necessária às novas experiências e desafios.

A relação educativa se constitui em um processo na qual as mediações são planejadas de forma a possibilitar a aprendizagem, mas não é qualquer mediação que produz resultados efetivos, assim como não basta conhecer o substrato biológico do desenvolvimento humano para conhecer o caminho do desenvolvimento da espécie (DE CARLO; BARTALOTTI, 2001, p. 108).

O papel do pedagogo para alunos/pacientes em idade de escolarização que estão hospitalizados é muito importante, uma vez que o processo de ensino e aprendizagem também ocorre neste ambiente que, mesmo sendo no âmbito do hospital, é escolar e contribui com suas práticas docentes para a formação desses alunos.

Segundo Matos e Mugiatti (2014, p. 73), faz-se necessário que o homem molde às suas necessidades, neste sentido, possibilitando uma ruptura do paradigma para evolução, relacionando que: "escola só em sala de aula e hospital apenas para tratamento médico", e neste aspecto o pedagogo hospitalar será um agente de mudança uma evolução para um novo contexto no aprimoramento do atendimento hospitalar.

No ambiente hospitalar, o atendimento educacional determina um desejo de mudança, de inclusão, "no mundo transformado pela tecnologia mais do que nunca a educação deve estar apoiada na busca de alunos e 
professores inventivos e criativos, capazes de preconizar uma sociedade melhor" (BRANDÃO, 2002, p.4).

Não é mais possível ignorar o fato de que a tecnologia tenha transformado rotinas do dia a dia, e que professores e alunos, ao se utilizarem da tecnologia, não fiquem restritos a participações passivas diante dela mesma, mas que saibam usá-la, incorporando-a na busca e no desenvolvimento de novos saberes.

É desta forma que "um ambiente de aprendizagem poderá ser muito rico, porém, se o aluno não desenvolve atividades para o aproveitamento de seu potencial, nada acontecerá" (GALVIS, 1992, p. 52). Neste sentido, o ambiente de aprendizagem torna-se um espaço que possibilita a construção de atividades a serem realizadas pelo aluno, que apoiado num planejamento, deverá nortear a ação pedagógica para que ela seja efetiva.

O professor deve interagir com os alunos, saber utilizar as TIC e delas tirar vantagens, principalmente para assegurar a seus alunos o conhecimento que os levará a serem cidadãos com competências e habilidades para participarem dos processos da sociedade digital (OLIVEIRA, 2007, p.16).

A tecnologia está cada vez mais presente no nosso cotidiano, bastando-nos saber melhor aproveitá-la, tirando as vantagens pedagógicas possíveis presentes nesta ferramenta. Percebe-se ainda que tem crescido o número de adeptos à sua inclusão como forma de agilizar a atividade docente, estabelecendo uma comunicação mais próxima com os pais e buscando motivar os estudantes em sala de aula.

Um desafio por vezes inesperado nesse processo é a resistência de professores em adotar tais recursos. Talvez pela forma que esse recurso lhe seja trazido, por falta de capacitação e convencimento dos benefícios que a tecnologia pode trazer para a sala de aula, sendo preciso discutir com os pares e analisar cada estratégia de aplicação das TICs no meio educacional como mediadoras do conhecimento. 
Essa educação escolar, no entanto, aliada ao poder governamental, detém para si o poder de definir e organizar os conteúdos que considera socialmente válidos para que as pessoas possam exercer determinadas profissões ou alcançar maior aprofundamento em determinada área do saber. [...] Por sua vez, na ação do professor na sala de aula e no uso que ele faz dos suportes tecnológicos que se encontram à sua disposição, são novamente definidas as relações entre 0 conhecimento a ser ensinado, o poder do professor e a forma de exploração das tecnologias disponíveis para garantir melhor aprendizagem pelos alunos (KENSKI, 2014, p. 19).

A escola precisa estar atenta às necessidades do estudante de hoje, que interage com o conteúdo de forma mais participativa. Esse estudante que interage com os outros, que cria e enfrenta sempre novos desafios, precisará para que exista interação, além do conhecimento e/ou vontades, a observância de valores e comportamentos que geram hábitos que envolvam a educação.

A atuação do professor a partir desta perspectiva será a de desenvolver uma proposta pedagógica indicada para cada aluno, conforme suas necessidades, interconectando os saberes acadêmicos e os experienciados, numa dinâmica dialética de sua práxis educativa, onde no ambiente hospitalar, por ser uma atividade cotidiana com experiências, multi/inter/transdisciplinar, torna-se ainda mais desafiador.

A evolução tecnológica não se restringe apenas aos novos usos de determinados equipamentos e produtos. Ela altera comportamentos. A ampliação e a banalização do uso de determinada tecnologia impõem-se à cultura existente e transformam não apenas o comportamento individual, mas o de todo o grupo social (KENSKI, 2014, p. 21).

O estímulo da criança para o uso das TICs se desenrola como práticas necessárias e atuais, gerando uma nova atitude a partir do aperfeiçoamento das ações pedagógicas bem planejadas, atuando em cooperação, onde a educação atue nos variados contextos de relações e interrelações dos sujeitos do processo educativo.

Esse processo educativo correlaciona-se aos mais variados locais e/ou ambientes, onde seus sujeitos estão num contínuo exercício de 
aprendizagem, e a educação seja, fora dos muros da escola, como na classe hospitalar ou na escola regular se dê em favor dos interesses dos educandos.

Educação e Saúde constituem-se em campo epistêmico de relevância para a qualidade de vida e cidadania nas esferas humana e social. Refletir sobre esse campo em suas dimensões e relações é uma necessidade, uma vez que a origem e a finalidade última de todo saber, em princípio, deve atentar para a existência humana (MORENO, 2015, p. 86).

Para Vygotsky (2002, p. 32), ao longo do desenvolvimento do homem, as causas de sua mudança estão vinculadas às interações que ocorrem entre o sujeito e a sociedade, a cultura e sua história de vida, aliadas as oportunidades de aprendizagem:

O desenvolvimento do sujeito humano se dá a partir das constantes interações com o meio social em que vive, já que as formas psicológicas mais sofisticadas emergem da vida social. Assim, o desenvolvimento do psiquismo humano é sempre mediado pelo outro (outras pessoas do grupo cultural), que indica, delimita e atribui significados à realidade (VYGOTSKY, 2002, p. 32).

As tecnologias surgem como uma realidade onde o docente poderá utilizá-las a seu favor. Usando ferramentas tecnológicas, no trabalho pedagógico hospitalar, na oferta de novas possibilidades de tarefas ao utilizar som, imagem, escrita e outras possibilidades de forma interativa, integrando o aluno/paciente com os diversos recursos tecnológicos.

Tecnologias da informação e comunicação deixam de ser encaradas como um mero recurso instrucional moderno e adquirem o status de fato gerador/provocador de uma nova pedagogia: centrada no aluno, orquestrada por docentes e gestores competentes, capaz de promover uma interatividade que derruba os limites físicos da sala de aula e contribui para formar o cidadão crítico, participativo, solidário e responsável (NEVES, 2005, p. 21).

Assim, "temos que esquecer o futuro para poder ter o futuro, ou seja, não adianta preparar os alunos para o amanhã que não se conhece, se o presente, por si mesmo, constitui um grande desafio a ser superado" 
(ALMEIDA, 2002, p.2), onde as TICs como ferramenta auxiliar às atividades pedagógicas, tanto nas salas de aula regulares como também no contexto hospitalar, possibilitem a educação de crianças e adolescentes, com professores atentos em compreender qual recurso terá melhor resultado, e quais softwares seus alunos terão maior facilidade para desenvolver suas atividades criando situações de aprendizagem.

[...] os alunos ganham autonomia nos trabalhos, podendo desenvolver boa parte das atividades sozinhas, de acordo com suas características pessoais, atendendo de forma mais nítida ao aprendizado individualizado (TAJRA, 2000, p. 45).

Mas para que essas atividades sejam alcançadas de forma a atender as expectativas educacionais, será preciso que além dos recursos disponibilizados, os professores recebam formação adequada no auxílio às atividades propostas.

\section{A metodologia no uso das tecnologias na Semear}

A pesquisa apresenta abordagem qualitativa, sendo realizada na Classe Hospitalar Semear, implantada pela Prefeitura da Cidade do Recife, em 2015 no Centro de Oncohematologia Pediátrica/CEONHPE do Hospital Universitário Oswaldo Cruz/HUOC, através de parceria com o Grupo de Ajuda a Criança Carente com Câncer/GAC-PE, parte integrante de nossa tese de doutoramento.

$\mathrm{Na}$ voz de Minayo (2016, p. 22), a pesquisa busca responder a questões particulares, trabalhando com o universo de significados, motivos, aspirações, crenças, valores, atitudes, o que corresponde a um espaço mais profundo das relações, dos processos e dos fenômenos que não podem ser reduzidos à simples operacionalização de variáveis.

A discussão sobre a formação docente da classe hospitalar, abre uma lacuna a ser preenchida quanto a ação pedagógica que se desenvolve no hospital, possibilitando a construção de políticas públicas voltadas a qualidade da formação desse professor, tanto na formação inicial quanto na continuada. 
A partir desses aspectos, segundo Martinelli (1999, p. 21), a referida abordagem indica possibilidades quanto à apresentação de mais do que índices, medianas, descrições, a busca de interpretações, mais do que coleta de informações, buscando o envolvimento dos sujeitos e suas histórias.

$\mathrm{Na}$ busca do melhor entendimento dos elementos utilizados na pesquisa, os dados foram tratados qualitativamente, tendo por procedimento do objeto a escolha de uma pesquisa bibliográfica e estudo de caso único, tendo por lócus a Classe Hospitalar Semear, estando em concordância e harmonia com o tema proposto.

Para Martins (2008, p. 9), o estudo de caso se oferece como um método muito utilizado em pesquisas qualitativas, desenvolvendo-se em uma situação natural, rica em dados descritivos, focalizando a realidade de uma forma complexa e contextualizada, proporcionando o aumento da compreensão e do entendimento sobre os eventos a serem estudados.

Quanto ao procedimento da coleta de dados e sua análise, recorremos à entrevista semi-estruturada, seguindo-se a sua análise textual a partir da análise das mensagens, de sua linguagem, e discursos, entre outros, os quais, segundo Moraes (2003, p. 191), descrever e interpretar são elementos concebidos em conjunto, compondo parte do esforço de elucidar a compreensão de um determinado fenômeno.

Complementando esta ideia, a entrevista semi-estruturada:

[...] favorece não só a descrição dos fenômenos sociais, mas também sua explicação e a compreensão de sua totalidade, além de manter a presença consciente e atuante do pesquisador no processo de coleta de informações (TRIVIÑOS, 1987, p. 152).

As tecnologias no espaço escolar estão presentes em pelo menos três setores desse ambiente sejam nas questões administrativas, a exemplo das matrículas dos alunos; na construção dos currículos, aulas, e avaliação e, na prática na sala de aula. Neste sentido o uso das Tecnologias precisa ser entendido pelos professores, não como uma ameaça a sua forma de ensinar, mas como um aliado na promoção do 
aprendizado, onde o professor é quem determina o conteúdo e o aluno é o sujeito que constrói o caminho para sua assimilação.

Para Sousa (2010, p. 90) o professor "deve buscar novas formas de ajudar o aluno, despertando o seu interesse, desafiando-o, levando a discussão e à ação-reflexão, auxiliando-o a descobrir o significado e o contexto do conteúdo abordado”. O fazer pedagógico estabelecerá entre conteúdos escolares e a realidade vivida na ambiência hospitalar a mediação entre o ensino e aprendizagem.

A Classe Hospitalar Semear possibilita a escolarização de meninos e meninas em tratamento de câncer, e dentre seu material pedagógico comum, entre os livros e cadernos, traz como parte da inovação, mesas educativas que auxiliam a alfabetização, jogos, tecnológicos, tablets, softwares educacionais, tudo que tem numa escola regular, para que eles (as) durante o tratamento possam continuar seu aprendizado com todos os recursos disponíveis.

É fácil observar que no ambiente de um hospital, uma das áreas mais singulares e que chamam bastante atenção é a pediatria, ainda mais num setor de Oncologia Pediátrica, onde a fragilidade das crianças nos induzem a crer em ações e cuidados extraordinários junto a esse aluno/paciente.

\footnotetext{
Em se tratando de uma aprendizagem em situação incomum, como em contexto hospitalar, é necessário analisar as possibilidades dos ambientes virtuais de aprendizagem para explorá-las, a fim de contribuir para o desenvolvimento de escolares hospitalizados (TORRES; MATOS; BORTOLOZZI, 2014, p. 205).
}

A compreensão da práxis pedagógica e do funcionamento dessas ferramentas tecnológicas, nos diversos espaços de difusão do conhecimento, com seus infinitos recursos é o primeiro passo para que seu uso venha a acontecer permitindo aos sujeitos dessa ação avançarem além daquilo que intuitivamente já alcançou no contato com estas ferramentas.

O que importa hoje em um hospital pediátrico é o bem estar bio-psico-sócio-cultural e educativo tanto de seus clientes como de todos os atores envolvidos. Todas as profissões e 
ações administrativas devem ter este mesmo objetivo (RODACOSKI; FORTE, 2014, p. 63).

Neste sentido, o apoio pedagógico diante da hospitalização, deverá gerar um melhor aproveitamento do aluno/paciente, e seu restabelecimento motivado pela assistência pedagógica que valoriza o indivíduo.

Narra uma aluna do $6^{\circ}$ ano, "Ainda bem que, com a classe hospitalar, encontrei apoio e atenção para estudar. Quando a doença foi descoberta, em agosto de 2015, pensei logo nos estudos. Graças a Deus, estou no tratamento e tendo aulas até hoje", para os professores e toda equipe, é preciso estar bem preparado (as) e capacitados (as) para assumir a regência das classes hospitalares.

Deve-se compreender não só os aspectos ligados ao uso das TICs, como o conhecimento das ferramentas, suas potencialidades, capacitação para realização da atividade pedagógica mediada por essas tecnologias etc., mas também aspectos emocionais que permeiam a relação entre os sujeitos envolvidos neste ambiente ainda em exploração.

Nesse contexto, a intervenção pedagógica a partir das ferramentas tecnológicas disponibilizadas na classe hospitalar poderá auxiliar estes alunos/pacientes quanto a esperança e ressignificação dos seus valores, potenciais sonhos interrompidos pela internação, fortalecendo um elo com a educação e sua consequente socialização e inserção num mundo tão adverso para ele.

Conforme percepção das professoras da classe esses recursos são muito importantes: "Hoje utilizamos tablets, mesas educativas e notebooks, que ajudam na aprendizagem, e que muitas vezes são levados para os leitos quando as crianças estão debilitadas, não podendo freqüentar a sala de aula."

Para melhor auxiliar as atividades didáticas, foram disponibilizados brinquedos pedagógicos, kits de literatura e impressora colorida. "Tudo para trazer mais cor para vida dessas crianças" conta um sujeito da equipe. Sendo importante destacar que a iniciativa está amparada em decreto e instrução normativa, que definem e regulamentam o trabalho. 
Não bastando a inserção de alunos com necessidades educacionais especiais na escola, em particular nas classes hospitalares, será preciso a oferta de condições para a operacionalização desse projeto pedagógico inclusivo e crucial a contínua formação docente, para sua atuação neste novo ambiente telemático, de múltiplas variáveis, onde a tecnologia e o professor se apresentam mediando o processo de ensino e aprendizagem.

FIGURA 1: Visão da mesa educacional alfabeto.

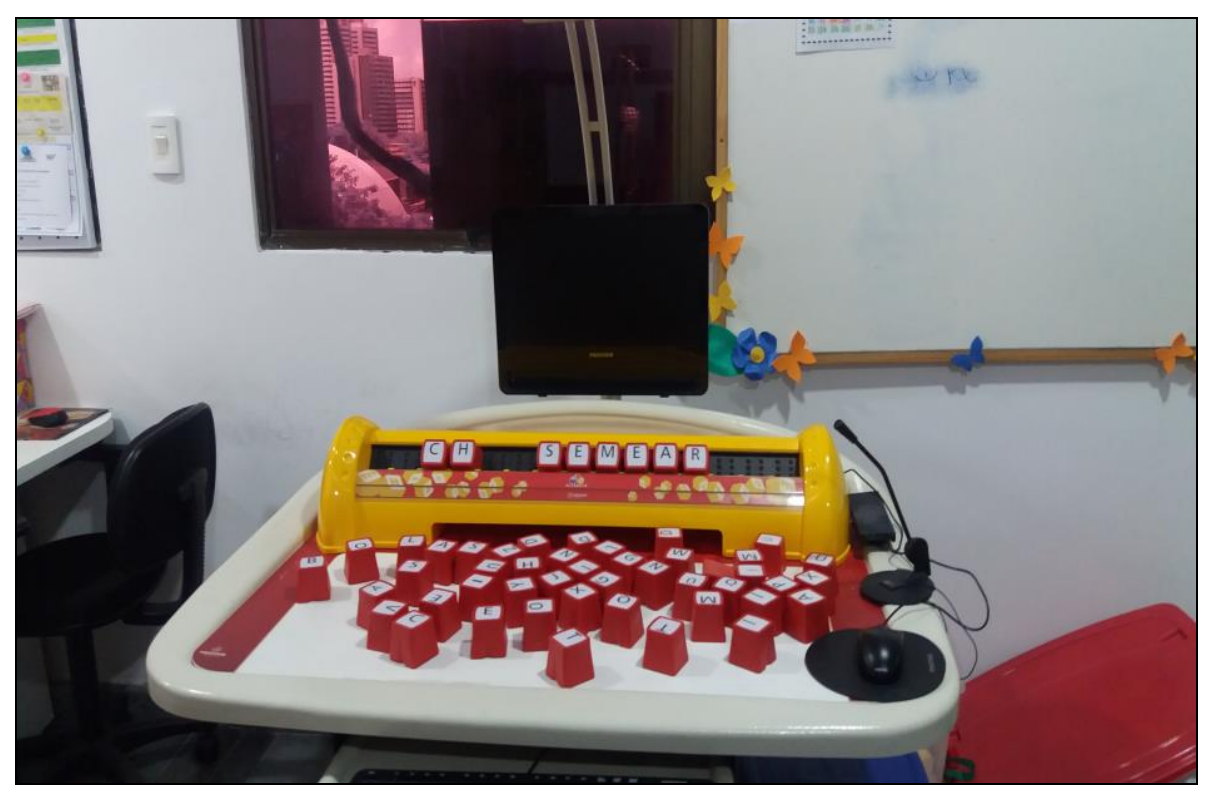

Fonte: Acervo dos autores (2020).

Segundo uma docente a classe utiliza-se dessas tecnologias, "com apoio dos materiais como a mesa de alfabeto eletrônica, a qual trabalha no processo de ensino e aprendizagem da alfabetização, tablets e computadores com fins de realizar pesquisas, buscar mídias interativas, além de utilizar aquelas oriundas do equipamento, acessando vídeos e sites com atividades pedagógicas de todas as áreas de conhecimento".

$\mathrm{Na}$ Mesa de alfabeto eletrônica é possível atuar nas áreas de atividades que apoiam o processo de alfabetização e letramento, com a possibilidade de identificação de cada letra de uma palavra, pelo som emitido. A mesa possui softwares educacionais e elementos de hardware em ambiente colaborativo, permitindo o desenvolvimento de habilidades cognitivas. 
De acordo com as professoras da classe: "A mesa contempla programas específicos ligados à alfabetização e letramento, o material também contempla o trabalho com habilidades mentais utilizando-se de conceitos matemáticos, como números e operações, espaço e forma, grandeza e medidas, dentre outros."

$\mathrm{O}$ uso das tecnologias instiga alunos e professores a construírem saberes e entenderem como podem interagir com os diversos setores da sociedade, favorecendo o processo de ensino e aprendizagem ao trabalhar os diversos conteúdos das disciplinas, deixando de lado a desatenção quando começam a raciocinar de forma intuitiva e lógica essas ferramentas que se tornam um caminho viável atuando na superação da ideia de aquisição passiva de informações, tornando-se um instrumento facilitador do ensino e da aprendizagem mais reflexiva, colaborativa e crítica.

Para uma das professoras da classe "a escolha de programas de computador educativos (softwares), deve ser criteriosa, devendo atender não só aos conceitos e concepções estabelecidas em planejamento curricular, como também, prevendo-se nessa programação a capacitação de seus professores", que na visão de Tajra (2007, p. 122) "Os professores devem ser capacitados, precisam ser capacitados e é a mola mestre para o sucesso de implantação desses recursos no ambiente educacional".

As aulas consideram as orientações clínicas, que indicam a disponibilidade para a atividade ponderando também os níveis de mobilidade dos pacientes. Havendo necessidade, eles são atendidos no próprio leito. A organização didática leva menos em conta a carga horária comumente exigida nas escolas regulares e prioriza os conteúdos e atividades que integrem as áreas de conhecimento e as situações lúdico-pedagógicas.

Segundo outra Professora da Classe: "Os professores desenvolvem, juntamente com as crianças e adolescentes, atividades e seguem o planejamento escolar, conteudístico, idealizados pelas escolas de origem dos alunos ou desenvolvidos junto à Prefeitura de cada cidade. Assim, cada aluno tem um portfólio, com informações sobre atividades executadas e 
desenvolvimento cognitivo e, a partir desta documentação e provas escritas, enviadas pelas escolas de origem, os alunos são avaliados”.

A modalidade de ensino hospitalar apresenta-se a partir de uma organização flexível de suas atividades, de seus conteúdos e de adaptações curriculares, onde:

A complexidade na construção do saber em todos os segmentos, no ensinar para esse cenário, supõe comunicação, parceria, desafio, autonomia e exercício da cidadania. Educar para o exercício da cidadania significa percorrer caminhos desconhecidos, promovendo entendimentos e perspectivas sociais e existenciais (MUTTI, 2016, p. 132).

Nas palavras de uma professora "o uso desses equipamentos tecnológicos é imprescindivel para os estudantes/pacientes que se encontram no internamento, em particular, quando se encontram, por exemplo, com a mão de escrita com "acesso" (processo invasivo, para administração de fluidos de forma contínua) impedindo o uso de lápis e papel".

É neste sentido que as tecnologias na educação em especial na educação inclusiva, como conhecimentos científicos, trazem técnicas e instrumentos que colaboram no processo de ensino e aprendizagem do estudante com necessidades educacionais especiais, favorecendo a individualização do atendimento pedagógico em espaços de aprendizagem, não regulares, ou cujos grupos de estudantes apresentem níveis de desenvolvimento cognitivo e diversidades de necessidades específicas de aprendizagem, comuns das classes hospitalares. 
FIGURA 2: Visão da classe hospitalar.

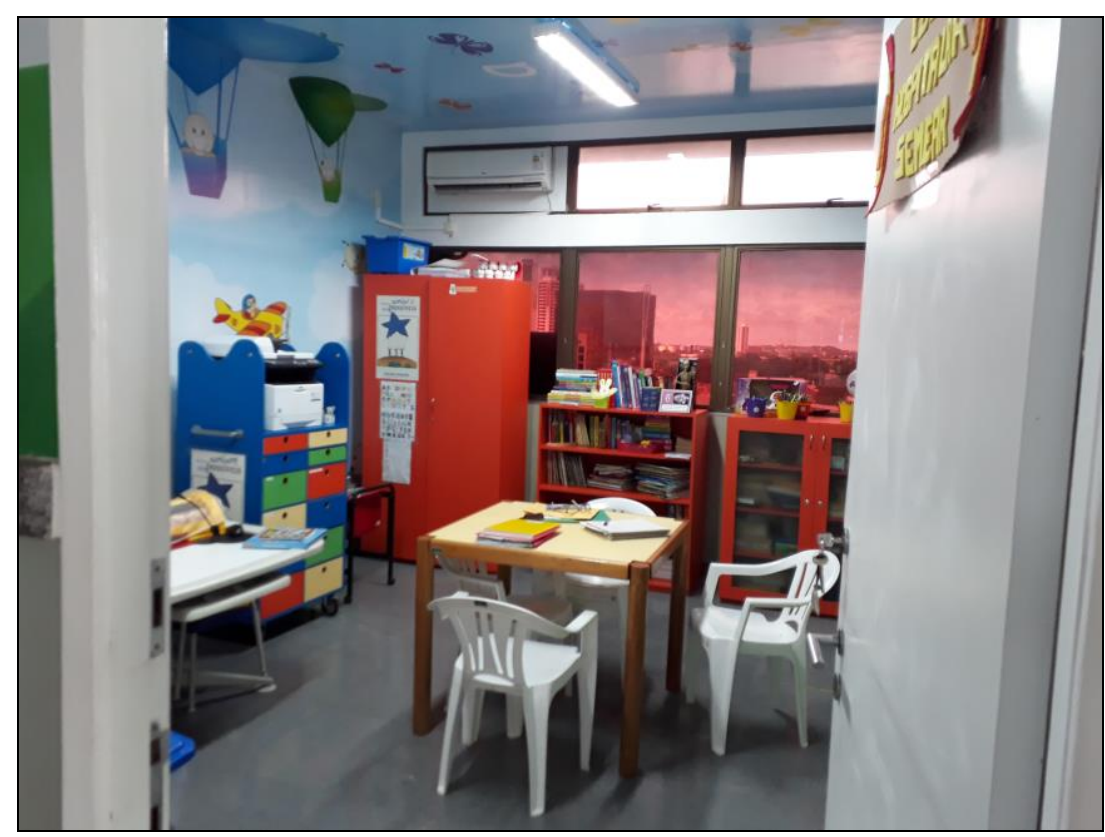

Fonte: Acervo dos autores (2019).

Mais recentemente a Classe Semear, de forma contextualizada introduziu o uso de material de robótica e Lego, com objetivos pedagógicos, atribuindo significado ao conhecimento. Quando solicitado, o Robô humanoide "NAO" (inovação tecnológica da Prefeitura da Cidade do Recife) é mais uma ferramenta aliada as práticas de ensino e ao projeto pedagógico.

A ação docente mediada pelas tecnologias é uma ação partilhada. Já não depende apenas de um único professor, isolado em sua sala de aula, mas das interações que forem possíveis para o desenvolvimento das situações de ensino. Alunos, professores e tecnologias integrando com o mesmo objetivo geram um movimento de descobertas e aprendizados (KENSKI, 2014, p. 105).

Os alunos/pacientes, sejam crianças, adolescentes, estão mergulhados nesse mundo repleto de informações, cheio de inovações tecnológicas, não podendo o professor se excluir diante dessas oportunidades tecnológicas.

Múltiplos enfoques e perspectivas definem e hierarquizam as posturas do professor. Estudos experimentais, comparativos, históricos e teóricos proporcionaram, e vêm proporcionando, inventários de tarefas, funções, perfis que, de qualquer modo, implicam atitudes profissionais assumidas, tentando 
analisar como os docentes são capazes de identificar dificuldades (RODRIGUES, 2012, p. 38).

De forma crítica e aliadas as práticas de ensino, os recursos digitais conviverão no ambiente escolar, possibilitando a dinamização do ensinoaprendizagem de forma criativa, auxiliando os professores a despertar a curiosidade dos estudantes, desenvolvimento as relações de socialização numa área, por essência, multidisciplinar, na perspectiva da promoção de benefícios aos atores sejam eles: alunos/pacientes, equipe de saúde, acompanhantes e visitantes, especialmente os primeiros que tem suas necessidades pedagógicas contempladas.

\section{Conclusões}

É grande o desafio à elaboração de estratégias pedagógicas que trabalhem com a tecnologia no âmbito da classe hospitalar, a começar pela construção de um vínculo emocional e humanístico para pacientes e familiares que, não raro, apresentam desordens emocionais e/ou psicoafetivas que podem prejudicar tal processo no espaço hospitalar na inserção das novas tecnologias. Porém esse é um caminho promissor no auxílio a promoção da aprendizagem dos alunos, ao tempo em que instigam e promovem nos professores um fator motivacional para o ensino, evidenciada pela dinâmica no uso das TICs.

A mediação pedagógica com apoio das TICs na Semear, permitiu perceber a individualidade dos sujeitos envolvidos, respeitando os aspectos emocionais e afetivos, geradores de desenvolvimento cognitivo destes pacientes/estudantes, a partir de abordagens sistémicas e multidimensional valorizando as relações do processo educativo.

Observamos que a Classe Hospitalar, possuindo uma ecologia própria em sua realidade pedagógica do cotidiano, os professores necessitam desenvolver planos de aula que considerem a especificidade dessa modalidade de ensino, fazendo as adaptações curriculares dos conteúdos enviados pela escola de 
origem, bem como definir os dispositivos e tecnologias que darão corpo e vida ao aprendizado de cada aluno/paciente de uma turma multisseriada, através de metodologias e estratégias adaptadas aos atendimentos pedagógicos realizados âmbito do hospital tanto no leito quanto na classe.

A identificação das ferramentas de ensino, sua disponibilização e a oferta de formação aos professores, possibilitarão um maior aproveitamento qualitativo para professores e alunos no decorrer do processo didáticopedagógico. Favorecidos pela atratividade desses recursos tecnológicos, as aulas se tornarão mais leves, específicas e interativas.

A Classe Hospitalar Semear levando-se em conta o ideário de uma pedagogia hospitalar de atenção integral do aluno/paciente, valoriza o trabalho pedagógico com atividades lúdicas, tornando os pacientes mais leves, tirando-o por vez da realidade do hospital, contribuindo para a relação intra e interpessoal, não se limitando à escolarização desse aluno, mas, sua atuação multidisciplinar, possibilita que a criança possa ser levada a compreender seu cotidiano hospitalar, de modo que esse conhecimento e emoções, viabilizem o aprendizado.

$\mathrm{O}$ uso de tecnologias com mediação pedagógica adequada a essa modalidade de ensino possibilita a construção do conhecimento de forma lúdica, prazerosa, divertida associada às dinâmicas de socialização, indispensáveis a esse ambiente pedagógico. Ultrapassando o enfoque tradicional de ensino, que privilegia a memorização de conteúdo.

É preciso experimentar na prática situações que levem os alunos a utilizarem as TICs não apenas como ferramenta auxiliar, mas sim como recurso primário levando-o ao conhecimento de forma plena e neste sentido nos ambientes escolares as novas tecnologias deve definir e construir um ambiente de ensino, onde a aprendizagem efetivamente ocorra.

O uso do computador na classe hospitalar destaca-se como um importante recurso tecnológico, promovendo a acessibilidade ao currículo, garantindo a participação do estudante/paciente nas atividades educativas, 
sendo usados de forma integrada a estratégias metodológicas, objetivando o desenvolvimento de habilidades essenciais para os estudantes.

Vivenciamos o zelo na Classe Semear, para além do direito ao atendimento pedagógico, à humanização do hospital e seus sujeitos, com as possibilidades educacionais da criança e demais atores, através do empenho de toda equipe multidisciplinar na mediação do conhecimento e sua transmissão envolvendo o aluno/paciente no processo de aprendizagem.

\section{Referências}

ALMEIDA, M. E. B. de. Gestão Escolar e Tecnologias - Formação de gestores para o uso das Tecnologias da Informação e Comunicação. São Paulo: Loyola, 2002.

ALMEIDA, M. E. B. de. Prática e formação de professores na integração de mídias. In: ALMEIDA, M. E. B. de \& MORAN, J. M. (orgs). Integração das tecnologias na educação. Salto para o futuro. Secretaria de Educação a Distância: Brasília, Seed, 2005. p. 124-127.

BARROS, A. S. S.; SANTOS, R. M. Percepções dos professores da educação especial acerca das crianças e adolescentes hospitalizados. CONGRESSO BRASILEIRO DE EDUCAÇÃO ESPECIAL, 3., São Carlos, Anais..., 2008. Disponível em:

$<$ http://www.cerelepe.faced.ufba.br/arquivos/fotos/134/barrosemaltez.pdf $>$. Acesso em: 04 fev. 2020.

BRANDÃO, E. Informática e educação: uma difícil aliança. Passo Fundo: UPF, 1995.

BRASIL. O Censo Escolar - Notas Estatísticas: Censo Escolar. Brasília: INEP, Ministério da Educação, 2018. Disponível em:

$<$ https://download.inep.gov.br/educacao_basica/censo_escolar/notas_estatisticas/2 018/notas_estatisticas_censo_escolar_2018.pdf>. Acesso em: 25 jan. 2021.

COLL, C.; MAURI, T.; ONRUBIA, J. A Incorporação das tecnologias da informação e da comunicação na educação: do projeto técnico-pedagógico às práticas de uso. In: Coll et al. Psicologia da educação virtual: aprender e ensinar com as tecnologias da informação e da comunicação. Porto Alegre: Artmed, 2010

DE CARLO, M. M. R. P.; BARTALOTTI, C. C. (orgs.) Terapia Ocupacional no Brasil: fundamentos e perspectivas. São Paulo: Plexus, 2001. 
GALVIS, A. H. Ingeniería de software educativo. Santa Fé, Bogotá: Ediciones Uniandes, 1992.

HERNANDEZ, F. Um diálogo a partir da incerteza com três experiências de formação na escola. Tessituras, Caderno n. 1, PBH, SMED, 1998, p. 42-44.

KENSKI, Educação e Tecnologias: O novo ritmo da informação. $8^{\mathrm{a}}$. ed. $4^{\mathrm{a}}$ reimpressão, Campinas, SP: Papirus, 2014.

MARTINELLI, M. Conversando sobre educação em valores humanos. $3^{a}$ edição. São Paulo: Petrópolis, 1999.

MARTINS, G. A. Estudo de caso: uma reflexão sobre a aplicabilidade em pesquisas no Brasil. Revista de Contabilidade e Organizações, v. 2, n. 2, p. 918, jan./abr., 2008.

MATOS, E. L. M.; MUGIATTI, M. T. F. Pedagogia Hospitalar: a humanização integrando a educação e saúde. 7 ed. - Petrópolis, RJ: Vozes, 2014.

MORAES, R. Uma Tempestade de Luz: a compreensão possibilitada pela análise textual discursiva. Ciência \& Educação, São Paulo, v.9, n.2, p. 191 - 211, 2003.

MORAN, J. M. A Educação que desejamos: novos desafios e como chegar lá. Campinas, SP: Papirus Editora, 2007.

MUTTI, M. C. S. Pedagogia hospitalar e formação docente: a arte de ensinar, amar e se encantar. Jundiaí: Paço Editorial, 2016.

MINAYO, M. C. de S. et al. Pesquisa Social: Teoria, Método e Criatividade. Petrópolis: Editora Vozes, 2016.

MORENO, L. V. A. Educação e Saúde: a dignidade humana como fundamento da prática do docente em ambiência hospitalar. $1^{\mathrm{a}}$ edição. Curitiba: Appris, 2015.

NEVES, C. M. C. A pedagogia da Autoria. Boletim Técnico do SENAC, v.31, n.3, set./dez.2005.

OLIVEIRA, A. S. Perspectivas para formação de professores na sociedade da informação. In: MERCADO, Luis Paulo Leopoldo (org.). Percursos na Formação de Professores com Tecnologias da Informação e Comunicação na Educação (org.). Maceió: Edufal, 2007.

PEDROSA, E. M.; LUIZ, M. K. S. A construção de uma prática educativa através da tecnologia: um olhar para o ambiente hospitalar. EmRede Revista de Educação a Distância. v. 4, n. 1, p. 155-65, 2017. 
POZO, J. I. Aquisição do conhecimento: quando a carne se faz verbo. Artmed, Porto Alegre, 2005.

RODACOSKI, G. C.; FORTE, L. T. Prática pedagógica em complexo hospitalar. In: MATOS, E. L. M. (Org.). Escolarização Hospitalar: educação e saúde de mãos dadas para humanizar. $4^{\mathrm{a}}$ ed. Petropolis, RJ: Vozes, 2014.

SAMPAIO, M. N.; LEITE, L. S. Alfabetização tecnológica do professor. 2. ed. Petrópolis: Vozes, 1999.

SERAFIM, M. L.; SOUSA, R. P. Multimídia na Educação: o vídeo digital integrado ao contexto escolar. In: SOUSA, Robson P.; MOITA, Filomena M.; CARVALHO, Ana B. (Orgs.). Tecnologias digitais na educação. Campina Grande: Eduepb, 2011.

TAJRA, S. F. Informática na educação: novas ferramentas para o professor na atualidade. $7^{\mathrm{a}}$ ed. São Paulo: Érica, 2007.

SOUSA, Silvia Regina R. Educação e as novas tecnologias da informação e comunicação. Modulo IV do curso de Pedagogia em EAD, do Programa da Universidade Aberta do Brasil. Teresina-PI UFPI, 2010.

TORRES, P. L.; MATOS, E. L. M.; BORTOLOZZI, J. M. Eureka@ Kids Criatividade em contexto escolar e hospitalar. In: MATOS, E. L. M. (Org.). Escolarização Hospitalar: educação e saúde de mãos dadas para humanizar. $4^{\mathrm{a}}$ ed. Petropolis, RJ: Vozes, 2014.

TRIVIÑOS, A. N. S. Introdução à pesquisa em ciências sociais: a pesquisa qualitativa em educação. São Paulo: Atlas, 1987.

VYGOTSKY, L. A formação social da mente. 6. ed. São Paulo: Martins Fontes, 2002. 